\title{
Phagocytic and Bactericidal Properties of Normal
}

\section{Human Monocytes}

\author{
Roy T. Steigbigel, Lewis H. Lambert, Jr., and Jack S. Remington \\ From the Division of Allergy, Immunology, and Infectious Diseases, Palo Alto \\ Medical Research Foundation, Palo Alto, California 94301 and Department of \\ Medicine, Division of Infectious Diseases, Stanford University Medical Center, \\ Stanford, California 94305
}

A B S T R A C T The bactericidal and phagocytic capacities of monocytes for $E$. coli, Staphylococcus, Salmonella, and Listeria, and factors that influence these functions were evaluated and compared with those of the polymorphonuclear leukocytes of 30 normal human subjects. Monocytes killed a significantly smaller proportion of each of the bacterial species than did neutrophils from the same individuals. Whereas the neutrophils of all individuals demonstrated the ability to kill significant numbers of the four bacterial species, there was a marked variation in the effect of monocytes of different individuals on the growth curves of these same bacteria. When the bactericidal capacity of an individual's monocytes to more than one species of bacteria was examined in the same experiment, a significant difference in the effect of monocytes on the growth curve of one bacterial species as opposed to another was noted in 4 of 17 subjects. The bactericidal ability of monocytes of single individuals was consistent on different days in 9 of the 11 subjects whose monocytes were examined more than once against the same bacteria.

Studies were performed to determine if the lesser bactericidal capability of monocytes was due to a difference in the ability of monocytes and neutrophils to phagocytize or to a difference in the ability of these cells to kill ingested bacteria or both. The results demonstrated that monocytes phagocytize bacteria sig-

This work was presented in part at the Joint Session of the Infectious Diseases Society of America and the Twelfth Interscience Conference on Antimicrobial Agents and Chemotherapy, September 27, 1972.

Dr. Steigbigel is a Special Postdoctoral Research Fellow under the National Institutes of General Medical Science Grant 5F03 GM-51400-02.

Received for publication 27 February 1973 and in revised form 8 August 1973.

The Journal of Clinical Investigation Volume 53 January 1974·131-142 nificantly less well than neutrophils, but the intracellular killing capacity of both cell types is equal. Addition of phenylbutazone to cell suspensions completely inhibited intracellular killing by both monocytes and neutrophils, suggesting the possibility that the bactericidal mechanisms in both cell types might be similar.

Monocyte killing of $E$. coli, Salmonella, and Listeria, but not of Staphylococcus, was significantly diminished in heat-inactivated autologous serum. Neither increasing the concentration of autologous serum from $10 \%$ to $25 \%$ nor replacement of autologous serum with pooled human serum had any effect on monocyte killing of any of the four bacteria.

These studies demonstrate that peripheral blood monocytes are less bactericidal for the four bacterial species than neutrophils, solely because monocytes are less phagocytic. A baseline for further study of factors that influence monocyte function and for study of this cell in selected patient populations is provided.

\section{INTRODUCTION}

Although humans infected with intracellular bacteria (e.g., Salmonella, Listeria, $M$. tuberculosis, $M$. leprae and Brucella) frequently exhibit an increase in the number of peripheral blood monocytes (1), relatively little is known of the microbicidal capacities (2-5) of these cells. In animal models, resistance against infection with these facultative intracellular bacteria appears to be effected by the monocyte-macrophage system (6-8). The increasing morbidity and mortality due to facultative intracellular parasites in immunologically compromised patients (9) and the increasing interest in the role of the monocyte-macrophage system in defense against malignant growth $(10,11)$ indicated to us the need for a better understanding of the functional capacities of human monocytes. Knowl- 
edge of the relative and absolute phagocytic and bactericidal abilities of normal human monocytes and of factors that influence these functions would allow for a greater understanding of the role of monocytes in host defense.

We report here our findings of the bactericidal and phagocytic abilities of human monocytes against four species of bacteria and compare these abilities to those of polymorphonuclear leukocytes (neutrophils) of the same individuals. The influence of human serum on monocyte bactericidal ability and the variability of the function of these cells among different individuals and against different bacterial species are evaluated.

\section{METHODS}

Source and collection of blood. The blood studied was obtained from 30 normal volunteers ranging in age from 18 to $41 \mathrm{yr}$ (mean, $28 \mathrm{yr}$ ) ; 12 were men. None of the subjects was taking medication. $100-150 \mathrm{ml}$ of heparinized $(10 \mathrm{U} / \mathrm{ml})$ venous blood was collected through a 19-gauge needle and plastic disposable syringes and expressed into 250-ml siliconized Erlenmeyer flasks.

Preparation of leukocytes. Separate monocyte and polymorphonuclear leukocyte preparations were obtained by a slight modification of the technique of Böyum (12). Heparinized blood was immediately diluted $2: 1$ with $0.15 \mathrm{M}$ $\mathrm{NaCl}$, and carefully layered over $8 \mathrm{ml}$ of a mixture containing 24 parts of 9\% Ficoll (Pharmacia Fine Chemicals Inc., Uppsala, Sweden) and 10 parts of $33.9 \%$ Hypaque (Winthrop Laboratories, Div. of Sterling Drug, Inc., New York) in $40-\mathrm{ml}$ siliconized conical centrifuge tubes. The tubes were centrifuged at $400 \mathrm{~g}$ for $40 \mathrm{~min}$ at $20^{\circ} \mathrm{C}$. The mononuclear cell layer that appears at the interface of the Ficoll-Hypaque and plasma-saline layers was removed and washed twice in Hanks' balanced salt solution (HBSS), which had been preheated to $37^{\circ} \mathrm{C}$. The cells were then resuspended in a mixture of $50 \%$ heat-inactivated fetal calf serum (FCS) and $50 \%$ HBSS with $0.1 \%$ gelatin (Eastman Chemical Products, Inc., Div. of Eastman Kodak Co. Rochester, N. Y.). The total number of mononuclear cells (monocytes and lymphocytes) were counted in a hemacytometer. The proportion of cells that were monocytes was determined by counting those cells which had ingested $0.05 \%$ neutral red dye. The dye was considered to have been ingested if it appeared intracellularly in a globular pattern. In addition, cell type was determined by morphology in preparations stained with Wright's stain. The monocytes comprised $15 \%-31 \%$ (mean, $23 \%$ ) of the mononuclear cells.

After the mononuclear cell layer was removed, $10 \%$ by volume of $3 \%$ dextran (clinical grade, The Cutter Laboratories, Berkeley, Calif.) was added to the blood FicollHypaque mixture to sediment the polymorphonuclear leukocytes. Settling was allowed to take place in sterile, plastic, round-bottom beakers for approximately $45 \mathrm{~min}$. The granulocyte-rich supernate was removed and centrifuged at $200 \mathrm{~g}$ for $10 \mathrm{~min}$. The pellet was washed twice in $37^{\circ} \mathrm{C}$ HBSS and the cells resuspended in a medium containing

\footnotetext{
${ }^{1}$ Abbreviations used in this paper: CGD, chronic granulomatous disease; FCS, fetal calf serum; HBSS, Hanks' balanced salt solution.
}

$50 \%$ heat-inactivated FCS and 50\% HBSS with $0.1 \%$ gel (FCS-HBSS-gel). The number of neutrophils was determined by counting them in a hemacytometer. Contamination of the monocyte preparations by neutrophils and of the neutrophil preparation by monocytes was evaluated with Wright-stained smears, and was usually zero and never more than $0.05 \%$. The ability of monocytes to ingest neutral red dye and of greater than $99 \%$ of both cell types to exclude $0.1 \%$ trypan blue dye was used as evidence of cell viability.

Microorganisms. Staphylococcus aureus 502A and Escherichia coli were used as representatives of common grampositive and gram-negative organisms, while Listeria monocytogenes type $4 \mathrm{a}$ and Salmonella typhimurium (strain $\mathrm{C}_{5} \mathrm{~S}$ ) were used as representatives of gram-positive and gram-negative bacteria considered to be facultative intracellular parasites $(6-8) .^{2}$

All bacteria were cultured for $16 \mathrm{~h}$ in Trypticase soy broth (Baltimore Biological Laboratories, Baltimore, Md.). After centrifugation at $4,000 \mathrm{~g}$ for $10 \mathrm{~min}$ at $4^{\circ} \mathrm{C}$, they were washed twice in $0.9 \%$ saline and adjusted to an approximate concentration of $1 \times 10^{8} / \mathrm{ml}$ by measuring turbidity on a Bausch \& Lomb Spectronic 20 spectrophotometer set at $620 \mathrm{~nm}$ (Bausch \& Lomb Inc., Scientific Instrument Div., Rochester, N. Y.). The actual number of bacteria per milliliter was determined by plating and counting the number of colonies formed after $48 \mathrm{~h}$ of incubation at $37^{\circ} \mathrm{C}$.

Assay of the effect of phagocytic cells on bacterial growth curves. A modification of the method of Alexander, Windhorst, and Good was employed to evaluate killing of bacteria (13). Each bacteria-phagocytic cell-drug combination was assayed in duplicate in $12 \times 75-\mathrm{mm}$ plastic tubes (Falcon Plastics, Div. of B-D Laboratories, Inc., Los Angeles, Calif.). Each suspension contained $0.1 \mathrm{ml}$ of autologous serum, $0.3 \mathrm{ml}$ FCS-HBSS-gel, $0.1 \mathrm{ml}$ of HBSS containing $1 \times 10^{7}$ bacteria, and $0.5 \mathrm{ml}$ containing $5 \times 10^{8}$ cells (neutrophils or monocytes) in FCS-HBSS-gel. Control tubes containing the same concentrations of media, serum, and bacteria, but without phagocytic ce!ls, were run simultaneously. The tubes were rotated end over end (Roto-rack, Fisher Scientific Co., Pittsburgh, $\mathrm{Pa}$.) at 10 rotations $/ \mathrm{min}$ at $37^{\circ} \mathrm{C}$. At 2 and $4 \mathrm{~h}$, a $0.1-\mathrm{ml}$ aliquot was removed from each tube with an automatic micropipette (Oxford Labs, Foster City, Calif.). The sample was placed in $0.9 \mathrm{ml}$ isotonic saline and sonicated for $15 \mathrm{~s}$ at a level of $40 \%$ with the low probe setting of a Bronwill sonicator (Bronwill, Rochester, N. Y.) ; sonication effected release of intracellular bacteria and dispersed them so as to prevent clumping that might yield falsely low colony counts (14). Wright-stained smears of sonicated suspensions revealed that all of the phagocytic cells are disrupted by this method. The bacteria were not killed, as determined by plating of identical samples of bacteria before and after sonication at various intensities for varying periods of time. Sonication for $30 \mathrm{~s}$ at a setting of $85 \%$ did not influence viability of any of the bacteria. Appropriate tenfold dilutions were made of the sonicated suspension and spread on Trypticase soy agar. After incubation for $48 \mathrm{~h}$ at $37^{\circ} \mathrm{C}$, the number of colonies formed were counted.

To compare the effect of monocytes and neutrophils on

${ }^{2}$ Microorganisms were kindly provided as follows: $S$. aureus by Dr. Richard Stiehm, UCLA Medical School; E. coli by Dr. Kenneth Vosti, Stanford University Medical Center; L. monocytogenes and $S$. typhimurium by Dr. George Mackaness, Trudeau Institute, New York. 
the growth curves of bacteria, the data are expressed as the index $(I)$ :

$I=\left[\begin{array}{r}\text { viable bacteria in suspension of } \\ \text { cells }+ \text { bacteria }\end{array}\right] \times 100$.

At a given time period, the index compares the viability of bacteria cultured in the presence of phagocytic cells with the viability of bacteria cultured alone, rather than with the original inoculum. The index is used to express this data rather than the percentage of the original inoculum remaining at a time period. The index will distinguish between situations where the phagocytic cells have permitted growth of the bacteria to a number greater than the original inoculum, or to a number approximately equal to the original inoculum, or have effected a reduction of the bacterial numbers to below that of the original inoculum. The index will reflect the effect of the phagocytic cells on the growth of the bacteria while correcting for changes in bacterial growth that might occur from day to day, or any inhibitory effect that the medium (autologous serum) may have on bacterial growth. This index was employed rather than expressing the data as the number of bacteria present at a given time period compared with those present in the original inoculum since, in a significant number of instances, there was incomplete phagocytosis of bacteria by monocytes. In these instances, the influence of the medium on the viability of the bacteria will markedly affect growth curves. At any time period, the number of viable bacteria will depend on the combined effect of the phagocytic cells and the medium, and the index will reflect both of these effects. A representative example of how this index corresponds to growth curves is shown in Fig. 1. At $2 \mathrm{~h}$, the index was 72 for monocytes and 98 for neutrophils; at $4 \mathrm{~h}$, the index was 87 for monocytes and 99 for neutrophils.

Assay of phagocytic ability. The phagocytic abilities of neutrophils and monocytes were examined by adding antibiotics after $15 \mathrm{~min}$ of incubation to kill extracellular organisms (13). For Staphylococcus, Listeria, and E. coli, $0.1 \mathrm{ml}$ of HBSS containing $100 \mathrm{U}$ of penicillin and $100 \mu \mathrm{g}$ of streptomycin was substituted for $0.1 \mathrm{ml}$ of FCS-HBSSgel. For Salmonella, $200 \mu \mathrm{g}$ of ampicillin was added. Samples taken from the tubes containing antibiotics were washed twice in isotonic $\mathrm{NaCl}$ and centrifuged at $200 \mathrm{~g}$ for $10 \mathrm{~min}$ in a further attempt to remove extracellular bacteria, and to remove antibiotics from the cell pellet. The pellet was resuspended in $1 \mathrm{ml}$ of isotonic saline, sonicated, and processed like the samples without antibiotics.

To quantitate phagocytosis accurately, suspensions were prepared as described for bactericidal assays, but $0.1 \mathrm{ml}$ of HBSS containing $2 \mathrm{mg}$ of phenylbutazone (Ciba Pharmaceutical Co., Summit, N. J.) was substituted for $0.1 \mathrm{ml}$ of FCS-HBSS-gel. Duplicate controls of bacteria alone and bacteria with phenylbutazone were always run simultaneously; phenylbutazone at $2 \mathrm{mg} / \mathrm{ml}$ had no effect on the growth of the bacteria. Leukocyte viability was greater than $99 \%$ at $10 \mathrm{~min}$ after addition of phenylbutazone at 2 $\mathrm{mg} / \mathrm{ml}$, and decreased to $97 \%$ at $2 \mathrm{~h}$ and $90 \%$ at $4 \mathrm{~h}$. The effect of phenylbutazone upon phagocytosis by the monocytes and neutrophils of each subject was determined by counting the number of intracellular latex particles $(0.81$ $\mu \mathrm{m}$, Difco Laboratories, Detroit, Mich.) in stained preparations with and without phenylbutazone. Cytocentrifuge (Shandon Southern Instruments Inc., Sewickley, $\mathrm{Pa}$.) prep-

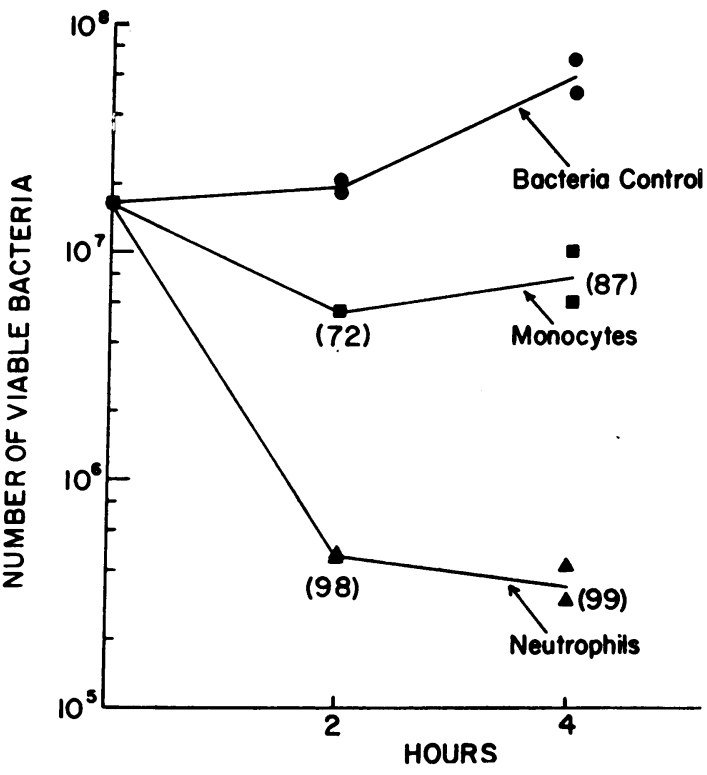

FIGURE 1 Representative example of the relationship between growth curves of bacteria alone and bacteria with phagocytic cells to indices. The indices are shown in parentheses at the 2 and 4 -h time period. The index is calculated from the mean of duplicate determinations of the number of viable bacteria in suspensions of bacteria with phagocytic cells and the number of viable bacteria in control suspensions at the same time periods. See text for formula.

arations were made after $45 \mathrm{~min}$ of incubation, which is the period of time that the phagocytic cells were incubated with Staphylococcus before the complete elimination of extracellular staphylococci by lysostaphin.

Lysostaphin (Schwarz/Mann Div., Becton, Dickinson \& Co., Orangeburg, N. Y.) at $1 \mathrm{U}$ in $0.1 \mathrm{ml} \mathrm{HBSS}$ was added at $30 \mathrm{~min}$ to tubes containing Staphylococcus alone, Staphylococcus plus cells, and Staphylococcus plus cells plus phenylbutazone. Each tube was run in duplicate and examined simultaneously. The tubes containing lysostaphin were washed twice in isotonic $\mathrm{NaCl}$ and centrifuged at $200 \mathrm{~g}$ for $10 \mathrm{~min}$ to remove serum that might inactivate trypsin. To inactivate any lysostaphin remaining after centrifugation, the cell pellet was resuspended in $1 \mathrm{ml}$ of $0.25 \%$ trypsin (Grand Island Biological, Oakland, Calif.) and incubated for $15 \mathrm{~min}$ at $37^{\circ} \mathrm{C}$ in a water bath. Samples were taken at 1,2 , and $4 \mathrm{~h}$ and sonicated, diluted, and plated as in the bactericidal assay. Bacterial survival or growth was not affected by $0.25 \%$ trypsin. The ratio

(phagocytic cells + bacteria + phenylbutazone

+ lysostaphin) $\times K$

original inoculum $[=$ bacterial control at $1 \mathrm{~h}]$

was used to express the proportion of available bacteria ingested by each cell type. At $1 \mathrm{~h}$ the control growth curve of Staphylococcus has the same number of bacteria as the original inoculum; therefore the original inoculum size is employed here as the denominator. $K$ is the factor that corrects for phenylbutazone inhibition of phagocytosis by the monocytes and neutrophils of each individual. The portion of ingested bacteria killed by monocytes or neutro- 
ESCHERICHIA COLI

SALMONELLA TYPHIMURIUM
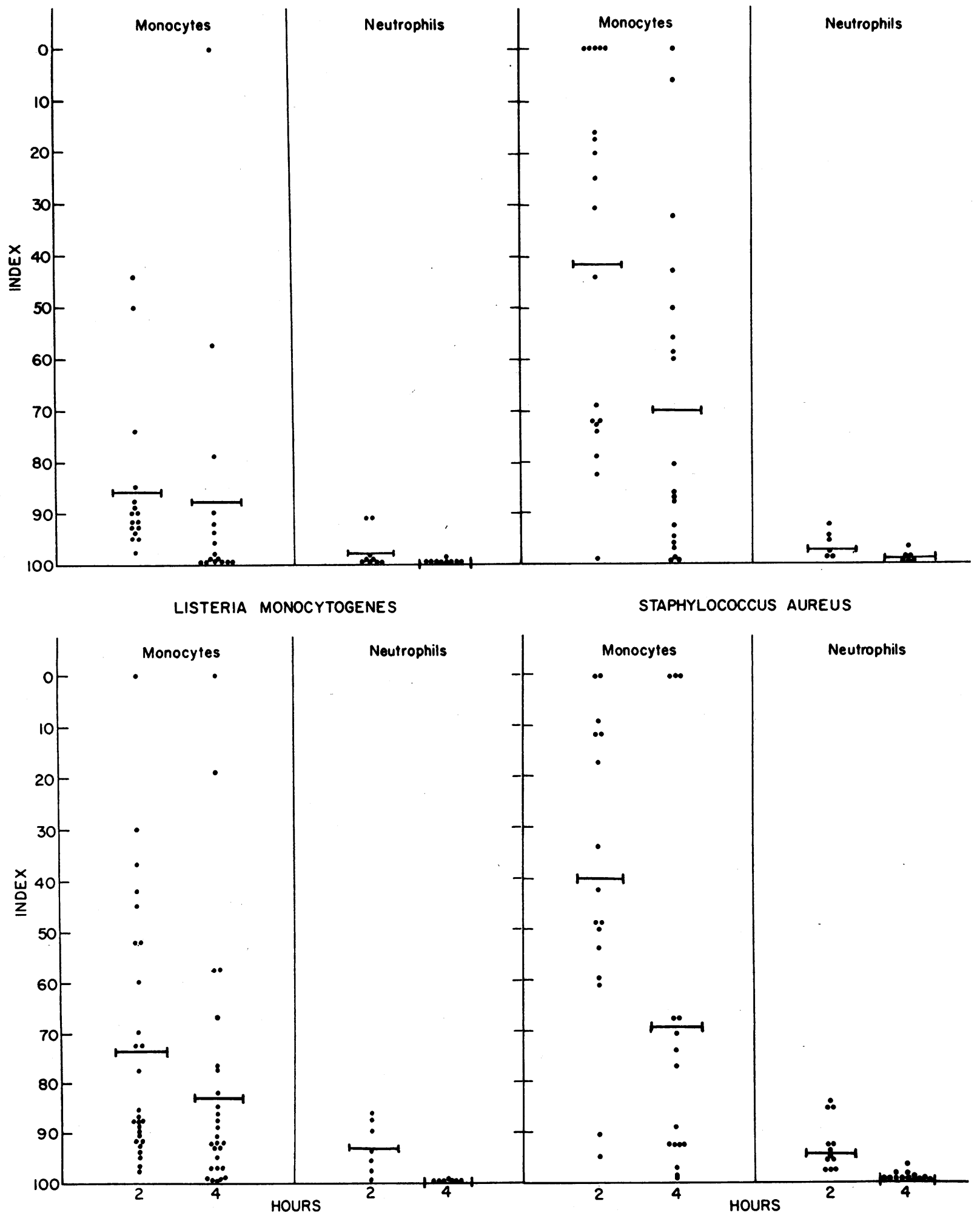

R. T. Steigbigel, L. H. Lambert, Jr., and J. S. Remington 
phils was derived from the ratio:

$A$ (phagocytic cells + bacteria + phenylbutazone + lysostaphin) $\times K$ minus $B$ (Phagocytic cells + bacteria + lysostaphin)

$A$ (phagocytic cells + bacteria + phenylbutazone

+ lysostaphin) $\times K$

$A$ represents all of the viable bacteria ingested by the phagocytic cells, and $B$ represents the ingested viable bacteria remaining after intracellular killing has proceeded for $1 \mathrm{~h}$.

Effect of serum. The single lot of heat-inactivated FCS employed had no demonstrable opsonizing effect on the four bacterial species in the presence of neutrophils or monocytes. The effect of monocytes and neutrophils on the growth curves of each of the four bacteria was studied simultaneously in pooled and autologous serum in five different subjects. Analogous studies were performed with or without heat inactivation in autologous serum in two different subjects for each of the four bacteria. The serum pool was from five normal persons, and was used either immediately after collection or was frozen at $-70^{\circ} \mathrm{C}$ and used within 2 wk of collection and immediately after thawing. At the time blood was collected to obtain phagocytic cells, the autologous serum was also collected, and a portion was heat-inactivated at $56^{\circ} \mathrm{C}$ for $45 \mathrm{~min}$. The effect of the absence of human serum on monocyte function was studied by comparing the bactericidal capacity of those cells simultaneously in the presence of only FCS and $10 \%$ autologous serum.

\section{RESULTS}

Effect of phagocytic cells on growth curves of bacteria. The indices for E. coli, Salmonella, Listeria, and Staphylococcus were obtained with equal numbers of monocytes and neutrophils of single individuals. The data are plotted in Fig. 2 to allow a comparison of results obtained with monocytes and neutrophils. Significantly fewer viable bacteria were consistently found in suspensions with neutrophils than in suspensions with monocytes from the same individuals $(P<0.001$; sign test [15]). The mean indices for both cells at 2 and $4 \mathrm{~h}$ are shown by the horizontal lines in Fig. 2 . In contrast to the observations with neutrophils, the bactericidal capacity of monocytes of different individuals varied such that the monocyte index of some individuals was equal to that of their neutrophils, whereas the monocyte index of others indicated that their monocytes had no effect on the growth of the bacteria. Because of the consistency of neutrophil indices for all four bacteria, it was considered unnecessary to study neutrophils and monocytes from each individual in every experiment. This accounts for the greater number of experiments with monocytes alone.
TABLE I

Variability in the Effect of Monocytes on Different Bacteria in the Same Experiment*

\begin{tabular}{clc}
\hline Subject & Organism & $\begin{array}{c}\text { Index } \\
\text { at } 4 \mathrm{~h}\end{array}$ \\
\hline D. F. & Listeria & 99 \\
& Staphylococcus & 0 \\
J. M. & E. coli & 92 \\
& Salmonella & 0 \\
J. G. & E. coli & 57 \\
& Salmonella & 6 \\
C. L. & E. coli & 96 \\
& Staphylococcus & 0 \\
& Listeria & 98 \\
\hline
\end{tabular}

* For each subject, monocytes were studied with each of the bacterial species in the same experiment.

The effect of monocytes and neutrophils on more than one bacterial species in a single experiment was examined in 17 individuals. In four of them, a significant difference in monocyte index was noted for different bacterial species (Table I). Differences in the control growth curves of the bacteria could not account for the differences in the indices; rather, they were due to the varying effect of the monocytes of these individuals on the four bacteria. In marked contrast were the results obtained with neutrophils of all 17 subjects; by $4 \mathrm{~h}$, the index was greater than $97 \%$ for all four bacterial species.

To determine if there is variability in the effect of monocytes on the same bacterial species on different days, the monocytes of 11 individuals were examined against a single bacterial species on more than one occasion. The data are shown in Table II. The variation in effect on different days did not reveal a difference of more than one-half $\log$ of organisms, except in 2 of the 16 series of determinations. In these two (R. S. with Staphylococcus and M. G. with E. coli) the variation was greater than a log of organisms.

Effect of serum. To determine if human serum is necessary for ingestion and killing of bacteria by monocytes, suspensions of monocytes, bacteria, and FCS were assayed simultaneously with or without $10 \%$ autologous serum. In the absence of human serum, at 4 $\mathrm{h}$ there was a greater than $90 \%$ decrease in monocyte killing of E. coli, Salmonella, and Listeria. In contrast, the effect of monocytes on Staphylococcus was the same in the presence or absence of human serum.

FIGURE 2 Monocyte and neutrophil index of the effect of the phagocytic cells on the growth curve of bacteria. Each dot represents a determination obtained with the cells of a single individual. The horizontal lines indicate the means. Direct visualization of stained smears of different people's mononuclear cells incubated with bacteria indicated a wide variation in the numbers of intracellular bacteria in the monocytes. 
TABLE II

Variability in Monocyte Function on Different Days

\begin{tabular}{llll}
\hline Organism & Subject & $\begin{array}{c}\text { Wk } \\
\text { after first } \\
\text { experiment }\end{array}$ & $\begin{array}{c}\text { Index at } 4 \mathrm{~h} \\
\text { in successive } \\
\text { experiments* }\end{array}$ \\
\hline Staphylococcus & L. L. & 12 & 71,93 \\
& G. T. & $9,19,28$ & $77,74,83,96$ \\
& G. D. & 7,16 & $83,99,92$ \\
Salmonellat & R. S. & 22 & 0,99 \\
Listerial & J. K. & 10 & 99,100 \\
& J. M. & 19 & 99,100 \\
& D. F. & 5 & 99,99 \\
& R. S. & 4 & 85,93 \\
& R. M. & 2 & 32,92 \\
& G. T. & 1,21 & $67,92,90$ \\
& J. K. & 15 & 97,97 \\
& C. L. & 26 & 98,91 \\
& J. K. & $6,16,17$ & $99,100,100,99$ \\
& J. M. & 9,16 & $92,98,79$ \\
& F. A. & 2 & 99,100 \\
& M. G. & 2 & 0,100 \\
\hline
\end{tabular}

* The initial figure in each line is the index noted in the first experiment.

When $10 \%$ and $25 \%$ autologous sera were tested in parallel to determine if increasing the amount of autologous serum would enhance the bactericidal ability of monocytes, no effect of the increased serum concentration was noted.

The bactericidal capacity of monocytes was studied in normal and heat-inactivated autologous serum in

TABLE III

Effect of Alternation of Human Serum on Monocyte Killing

\begin{tabular}{lcccc}
\hline & \multicolumn{4}{c}{ Effect on killing* } \\
\cline { 2 - 5 } Human serum & $\begin{array}{c}\text { Liste- } \\
\text { ria }\end{array}$ & $\begin{array}{c}\text { Salmo- } \\
\text { nella }\end{array}$ & $\begin{array}{c}E . \\
\text { coli }\end{array}$ & $\begin{array}{c}\text { Staph- } \\
\text { ylococ- } \\
\text { cus }\end{array}$ \\
\hline Heat inactivation & $\downarrow \downarrow$ & $\downarrow$ & $\downarrow$ & $0 \S$ \\
None\| & $\downarrow$ & $\downarrow$ & $\downarrow$ & 0 \\
$25 \%$ concentration & 0 & 0 & 0 & 0
\end{tabular}

* The effect of alterations of human serum in FCS-HBSS-gel medium on bacterial killing by monocytes was assessed at $2 \mathrm{~h}$ and $4 \mathrm{~h}$ by comparing the numbers of viable bacteria in cultures of bacteria alone in each medium with the numbers in cultures containing bacteria and monocytes in the same medium.

$\ddagger$ When compared with the results obtained in $10 \%$ normal, autologous serum, a decrease in killing by monocytes of $90 \%$ or greater was observed.

\$ When compared with the results obtained in $10 \%$ normal autologous serum, no difference in killing by monocytes was observed.

|| FCS-HBSS-gel without human serum. parallel, to determine if heat labile serum factor(s) influence monocyte function. The control included suspensions that contained bacteria alone in serum with or without heat-inactivation. In suspensions with monocytes, a significant (greater than 90\%) decrease in elimination of $E$. coli, Listeria, and Salmonella resulted from heat inactivation of the serum. No difference was noted in suspensions with monocytes and Staphylococcus, however. Neutrophil killing for all four organisms decreased significantly in heat-inactivated serum. The effect of serum on monocyte function is summarized in Table III.

Since the patient's serum employed in the assay may

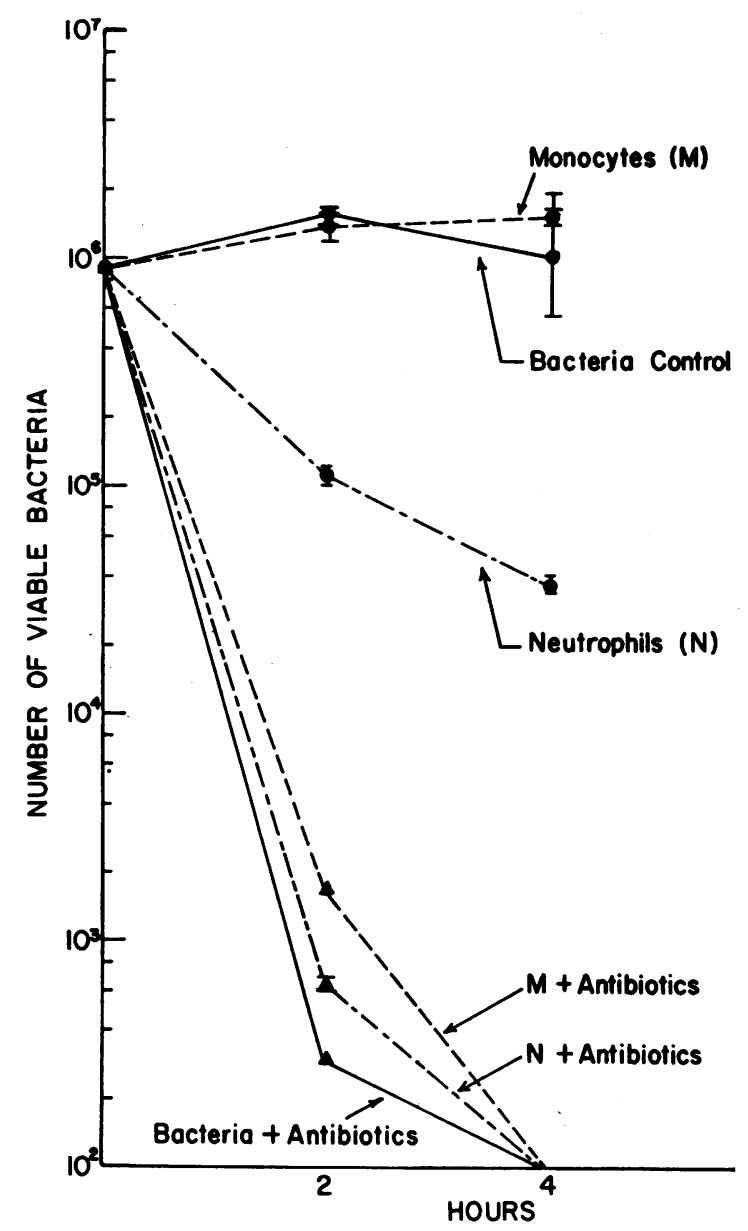

FIGURE 3 Evaluation of phagocytic capacity by the use of antibiotics in the medium. The growth curves are of bacteria (Staphylococcus) cultured in the presence of monocytes or neutrophils with or without antibiotics (penicillin and streptomycin) and of bacteria alone cultured with or without antibiotics. The inability of monocytes to protect bacteria from the antibiotics indicates that these cells did not kill the bacteria (upper monocyte curve is almost superimposable on growth curve of bacterial control) because they had not phagocytized them. 
be a limiting factor on the effect of monocytes on bacterial growth, a pool of serum was used to determine if it would alter the phagocytic or bactericidal activity. The substitution of pooled for autologous serum in five different subjects with each of the four bacteria did not alter the phagocytic or bactericidal capacity of monocytes.

Phagocytosis. To determine whether a difference in phagocytic ability might account for the differences in bactericidal capabilities of monocytes and neutrophils, studies were performed in which antibiotics were added to the bacteria-cell suspensions. The results of the single experiment depicted in Fig. 3 reveal that bacteria in the presence of monocytes exhibited a growth curve almost superimposable on the growth curve exhibited by bacteria alone. In contrast, there was a marked alteration in the growth curve of bacteria cultured in the presence of neutrophils: significant numbers were killed. These results do not allow one to differentiate whether the differences observed between the effect of neutrophils and monocytes on bacterial growth are due to a difference in intracellular killing ability or to a difference in phagocytic activity, or both. When antibiotics were added to the cultures to eliminate only extracellular bacteria, rapid killing of virtually all bacteria was noted in all tubes. The lack of protection of the bacteria from the antibiotics in cultures containing monocytes suggests that in these experiments the monocytes had not phagocytized the bacteria. The completely analogous curves seen with all four organisms indicate that monocytes do not phagocytize bacteria as well as neutrophils. From these experiments, one can conclude that the lesser capacity of monocytes to phagocytize is at least in part an explanation for their lesser bactericidal capacity.

To determine if there are differences in the intracellular killing ability of monocytes and neutrophils in addition to the differences in phagocytosis, and to quantitate the differences in phagocytosis found in the above experiments, phenylbutazone and lysostaphin were employed. In experiments in which simultaneous measurement of viable bacteria in suspensions of bacteria alone and in suspensions of bacteria with phagocytic cells and phenylbutazone were perfortmed, the phenylbutazone completely prevented intracellular killing by monocytes as well as by neutrophils. Examination of stained smears of phagocytic cells incubated with latex particles with or without phenylbutazone indicated that phenylbutazone inhibited monocyte phagocytosis by $46 \%$ (mean) and neutrophil phagocytosis by $58 \%$ (mean). Lysostaphin at $1 \mathrm{U} / \mathrm{ml}$ reduced an inoculum of $1 \times 10^{7}$ Staphylococcus to less than $10^{2}$ organisms in $15 \mathrm{~min}$ (Fig. 4) and thereby could rapidly remove all extracellular bacteria shortly after its addition. The

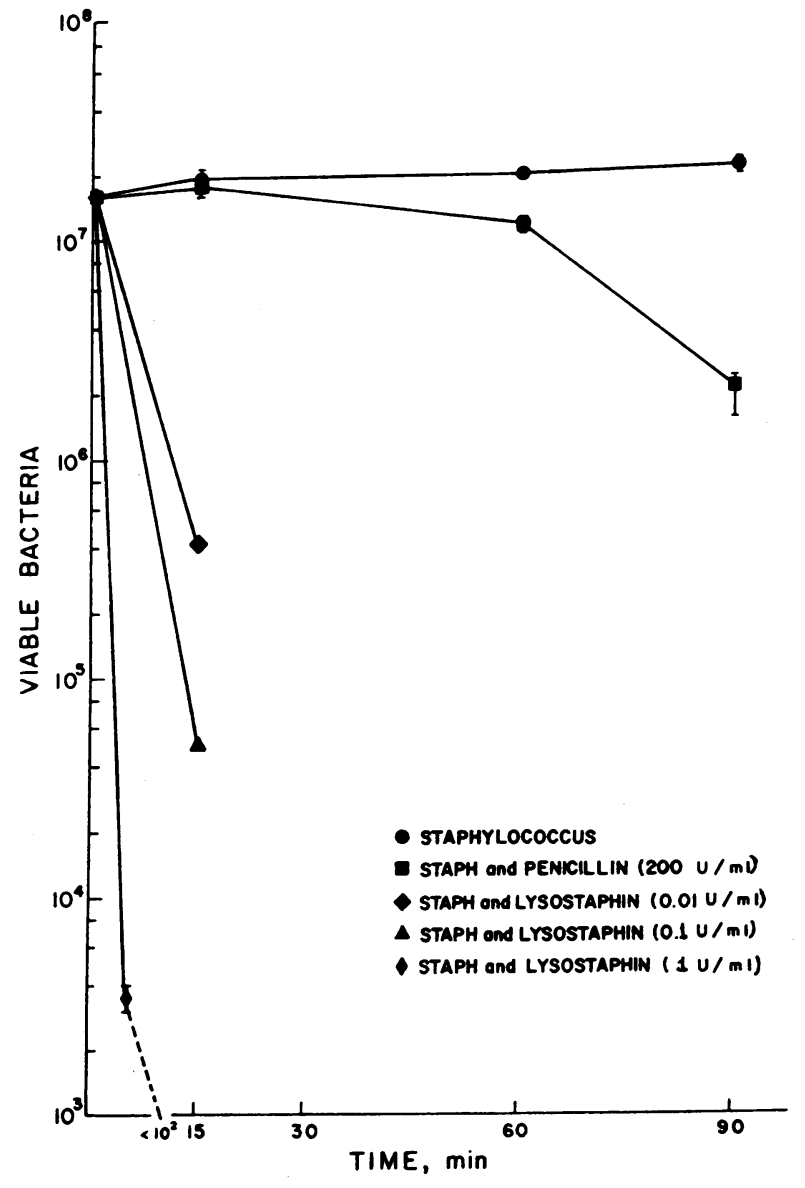

FIGURE 4 The comparative effect of lysostaphin and penicillin on the growth of Staphylococcus aureus during a period of $90 \mathrm{~min}$.

portion of bacteria phagocytized could be quantitated by measurement of the number of viable bacteria in suspensions of phagocytic cells and bacteria to which phenylbutazone and lysostaphin had been added. (See Methods.) The results of 10 experiments are shown in Fig. 5. Monocytes phagocytized a mean of $7.9 \%$ $(\mathrm{SEM}=2.3)^{\circ}$ of the available bacteria and neutrophils phagocytized $44.9 \%($ SEM $=5.9)$ of the available bacteria by the 1 -h time period $(0.5 \mathrm{~h}$ after addition of lysostaphin). This difference is significant $[P<0.001$, paired $t$ test (15)]. Monocytes killed 85.4\% ( $\mathrm{SEM}=$ 6.7 ) of ingested bacteria, while neutrophils killed $91.4 \%$ $(\mathrm{SEM}=2.5)$ by this same time period. This difference is not significant $(P>0.1)$. Since monocytes ingest fewer bacteria than neutrophils, we considered it necessary to decrease the number of bacteria in the neutrophil suspensions to compare the relative intracellular killing capacity of both cell types more accurately when there were equal numbers of intracellular bacteria. This was accomplished in three experiments, 


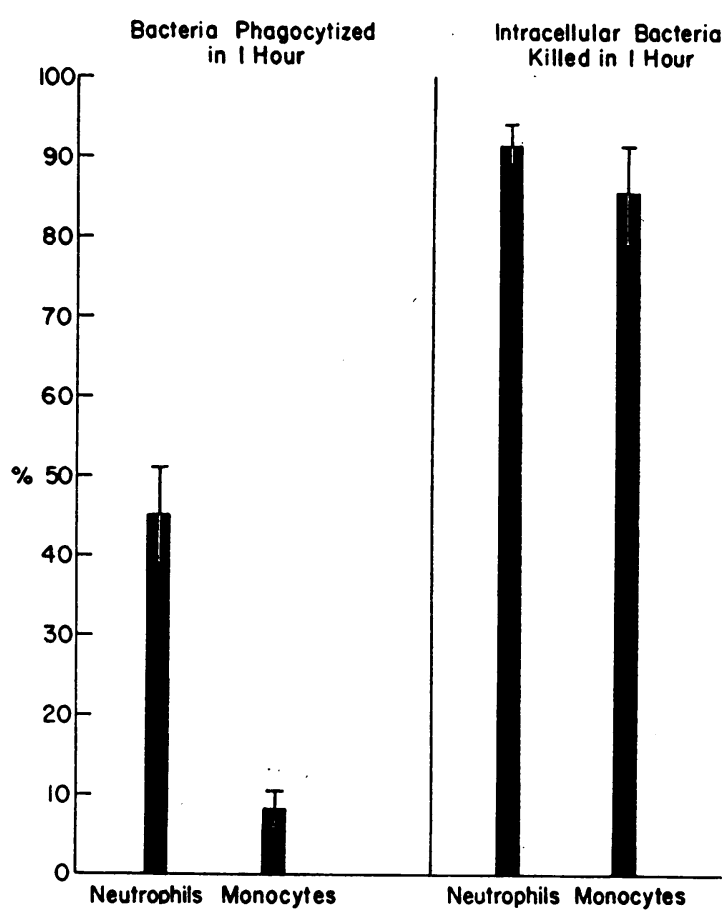

Figure 5 Results of quantitative studies on phagocytosis and intracellular killing of bacteria by neutrophils and monocytes. The large bars represent the percentage of the original inoculum that monocytes and neutrophils phagocytized after $1 \mathrm{~h}$ of incubation ( $\frac{1}{2} \mathrm{~h}$ after lysostaphin was added) in the presence of phenylbutazone, and the percentage of ingested bacteria killed by monocytes and neutrophils after $1 \mathrm{~h}$. The values are corrected for the inhibitory effect of phenylbutazone on phagocytosis.

and each time there was no difference between monocyte and neutrophil intracellular killing. These data suggest that monocytes are less bactericidal than neutrophils solely because they are less phagocytic.

\section{DISCUSSION}

These studies were performed to compare the phagocytic and bactericidal capacities of monocytes and polymorphonuclear leukocytes in the same individual. In each individual, neutrophils consistently exhibited a significantly greater and more rapid bactericidal capacity than did monocytes for each of the four bacterial species (E. coli, Listeria, Salmonella, and Staphylococcus). If these in vitro observations relate to the in vivo situation, the data suggest a greater role for the neutrophil against at least these bacteria in situations where both cells participate.

In the present study, equal numbers of monocytes and neutrophils isolated concurrently from the peripheral blood of normal adults were cultured in suspension rather than adhered to glass in an attempt to more nearly approach conditions of circulating phagocytes in vivo. Root, Rosenthal, and Balestra (3), in one of the few other studies employing suspension cultures, noted that monocytes from four normal subjects were less bactericidal for Staphylococcus aureus than were their neutrophils. Baehner and Johnston (4) found that the killing of Staphylococcus by leukocytes (less than $3 \%$ were neutrophils) from two children with congenital neutropenia and two with cyclic neutropenia was significantly less than that of an equal number of neutrophils from normal controls. These differences were similar to those observed between monocyte and neutrophil killing of Staphylococcus found in normals in the present study. Baehner and Johnston concluded that the lesser bactericidal capacity of the monocyte as compared to the neutrophil offered an explanation for the failure of compensatory monocytosis to protect against bacterial infection when neutrophil reserves are diminished.

In animal models, the circulating monocyte, the source of tissue macrophages (16), provides the host with the major effector cells (macrophages) in resistance against facultative intracellular bacteria such as Salmonella and Listeria $(7,8,17)$. Direct evidence for this derives from the observation that cyclophosphamide inhibition of production of monocytes prevented development of cellular resistance to Listeria in rats (18). Furthermore, in another study, Listeria multiplied in mouse livers that had large accumulations of neutrophils until monocyte-derived macrophages accumulated there (19). Our results indicate that while human monocytes are capable of some killing of Listeria and Salmonella in vitro, human neutrophils kill these bacterial species to a significantly greater degree. Furthermore, neutrophils killed Salmonella and Listeria as effectively as they killed $E$. coli and Staphylococcus. These observations suggest that the neutrophil may play a major role in defense against so-called facultative intracellular bacteria in man. Of interest in this regard are the results of Cline and Cohen $(20,21)$, who noted that human neutrophils in suspension killed a larger proportion of Listeria than did human "macrophages" (monocytes adhered to a glass surface for 4-10 days).

The influence that serum may play in the effect of monocytes on the growth curves of the bacteria was examined. When pooled human serum was substituted for autologous serum, no significant alteration in the phagocytic or bactericidal capacity of monocytes or neutrophils for the four bacteria was observed. When the concentration of human serum was increased from $10 \%$ to $25 \%$, no differences were noted in monocyte or neutrophil bactericidal function. That serum factors 
enhance the bactericidal function of human monocytes was shown in our studies in which monocyte killing of E. coli, Salmonella, and Listeria was reduced significantly in the absence of human serum. Heat lability of certain of these factors was shown in experiments in which heat-inactivated autologous serum or FCS was substituted for normal autologous serum. Although this did not alter the monocyte killing of Staphylococcus, it significantly altered monocyte killing of the other bacterial species. Apparent differences observed in the ability of the monocyte to kill different bacterial species (Fig. 2) may be explained, at least in part, by the varying inhibitory effect of the media (autologous serum) on extracellular bacteria. This difference cannot, therefore, be considered a property intrinsic to the cell itself.

Studies in which antibiotics were added to the suspensions revealed that monocytes phagocytize less well than neutrophils. To verify these data and to gain quantitative information on phagocytosis and intracellular bactericidal capacity of cells, it was necessary to quantitate all bacteria ingested. Addition of antibiotics that act extracellularly (22) to suspensions of phagocytic cells and bacteria is a relatively slow and inefficient means of eliminating bacteria (23), and therefore does not yield quantitative data. Prevention of intracellular killing with phenylbutazone and elimination of all extracellular bacteria with lysostaphin did provide quantitative data. The use of phenylbutazone and lysostaphin yields more representative qualitative and quantitative information about the phagocytic properties of monocytes and neutrophils than is possible by visual examination of several hundred phagocytic cells. Furthermore, visual examination of stained preparations frequently does not allow one to distinguish intracellular bacteria from those adhering to the surface of phagocytic cells (24).

Strauss, Paul, and Sbarra showed that phenylbutazone inhibited phagocytosis of $E$. coli by guinea pig polymorphonuclear leukocytes by approximately $50 \%$, and almost completely prevented intracellular killing (25). In the present studies, phenylbutazone inhibited phagocytosis of latex particles by human neutrophils by $58 \%$ and phagocytosis by human monocytes by $46 \%$. Since disintegration of ingested live or heat-killed staphylococci in phagocytic cells that were not treated with phenylbutazone precluded quantitation of phagocytosis by visual examination, latex particles were used to determine the degree of inhibition of phagocytosis by phenylbutazone. Solberg (26) successfully used phenylbutazone to prevent bacterial killing by human neutrophils and demonstrated its usefulness in assaying the bactericidal activity of these cells. When phenylbutazone was added to some of our cell-bacteria suspensions at the beginning of incubation, complete inhibition of intracellular killing by both neutrophils and monocytes was observed. This allowed for quantitation of phagocytized bacteria, once all extracellular bacteria could be eliminated. The ability of phenylbutazone to inhibit intracellular killing by monocytes suggests that the metabolic pathways it inhibits in polymorphonuclear leukocytes may be necessary for the expression of bactericidal activity of the monocyte as well (27).

Tan, Watanakunakorn, and Phair (23) demonstrated that lysostaphin, a muralytic enzyme that does not enter neutrophils (28), rapidly and efficiently eliminates extracellular Staphylococcus aureus. By using lysostaphin and phenylbutazone in combination, quantitation of both phagocytosis and intracellular killing for the entire population of phagocytic cells in suspension was possible. The results obtained with this method demonstrated that the ability of monocytes to phagocytize Staphylococcus was approximately $20 \%$ of that of neutrophils. However, once the bacteria were ingested, the ability to kill intracellular Staphylococcus aureus was essentially the same for monocytes and neutrophils. This was also demonstrated after adjustment of the number of bacteria available for phagocytosis so that neutrophils and monocytes contained equal numbers of intracellular bacteria. The lesser bactericidal capability of human monocytes thus appears to be due solely to the lesser phagocytic ability of the monocyte as compared to the neutrophil.

In the comparative study of monocytes of neutropenic children and of neutrophils of control subjects by Baehner and Johnston, phagocytosis and intracellular killing were also studied (4). They concluded that monocytes killed ingested Staphylococcus aureus to a lesser extent than did neutrophils. Differential centrifugation was used to separate nonphagocytized bacteria in an attempt to examine intracellular killing. They considered bacteria remaining in the cell pellet as reflecting intracellular killing capability, and found that bacteria associated with monocyte pellets were not killed as effectively as were those associated with neutrophil pellets. Differential centrifugation is an inefficient method for separating phagocytized from nonphagocytized bacteria (23). In Fig. 6, it can be seen that centrifugation of suspensions of bacteria and cells at $200 \mathrm{~g}$ as done by Baehner and Johnston will sediment extracellular bacteria. Because of the significant numbers of extracellular bacteria associated with the cell pellet, and because of the different phagocytic properties of monocytes as opposed to neutrophils, sampling from pellet-associated bacteria is, in effect, a measure not only of intracellular killing, but also of phagocytosis of bacteria 


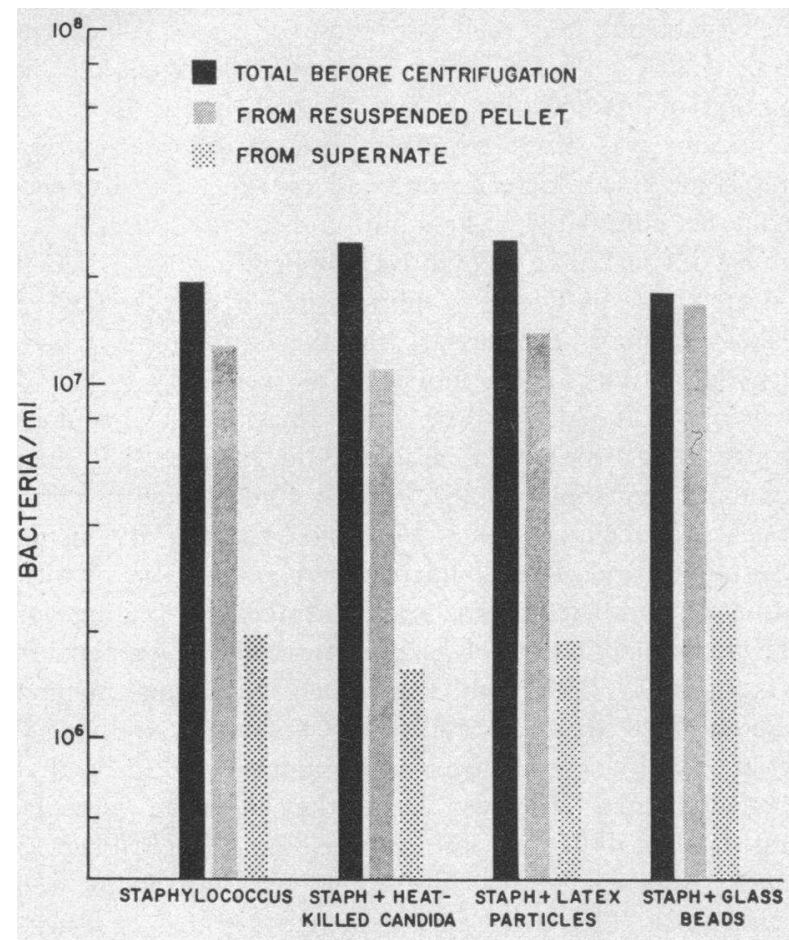

Figure 6 Effect of centrifugation at $200 \mathrm{~g}$ of suspensions of Staphylococcus aureus. After $10 \mathrm{~min}$ of centrifugation, greater than $95 \%$ of the bacteria were recoverable in the pellet. The presence of other particulate matter (Candida, latex particles, $75-150-\mu \mathrm{m}$ glass beads) did not appreciably alter the percent of bacteria recoverable in the pellet.

brought down with the pellet as well as of extracellular bacteria (Fig. 6): Therefore, Baehner and Johnston's data on pellet-associated bacteria reflect the greater phagocytic ability of the neutrophil as compared to the monocyte, and not intracellular killing alone. The neutrophils would have been able to more readily phagocytize and thereby reduce the number of bacteria in pellet suspensions than monocytes. This probably accounts for the discrepancy between their results and our own.

In the studies of monocyte function in children with chronic granulomatous disease (CGD) by Davis, Huber, Douglas, and Fudenberg (29) and Rodney, Park, Windhorst, and Good (30), antibiotics were added to cell-bacteria suspensions after $30 \mathrm{~min}$ of incubation. In their studies, monocytes from controls appeared to be as effective as neutrophils from controls in killing of Staphylococcus aureus. However, since our results, as well as those of Cline and Lehrer (2), Root et al. (3) and Baehner and Johnston (4), reveal that monocytes do not phagocytize bacteria as well as neutrophils, it is likely that the antibiotics in these studies and not the monocytes eliminated most of the organisms, which were in fact extracellular and never phagocytized. The data in Fig. 3 , which demonstrate this point, reveals that in the presence of antibiotics, the bactericidal capacities of monocytes and neutrophils appear the same. Without antibiotics, monocytes appear far less bactericidal than neutrophils. This indicates that the bactericidal capacity of the combination of antibiotics plus monocytes is due largely to the presence of antibiotics (since the bacteria were not phagocytized by the monocytes), and emphasizes the fact that antibiotic killing rather than monocyte killing will be measured if antibiotics are employed. If the antibiotics were not present in the test system employed by Davis et al. (29) and Rodney et al. (30), it would be expected that the monocytes would not have been as bactericidal for Staphylococcus as were the neutrophils, and their results would have been similar to those obtained in the present studies. The authors suggested that monocytes of children with CGD have a defect in intracellular killing similar to their neutrophils. Their results may also indicate that monocytes of children with CGD are more avidly phagocytic than are monocytes of normals. The monocytes of children with CGD may have protected more bacteria from antibiotics than control monocytes, and therefore phagocytized more bacteria than had monocytes of their control subjects.

In contrast to neutrophils, monocytes from different individuals were found to have different killing capacity for the same bacterial species.

Since monocytes functioned similarly in pooled or autologous serum, it does not appear likely that serum factors alone account for these variations. As human monocytes have receptor sites for complement and $\mathrm{IgG}$ (31), cell-bound antibody may play a role in the ability of monocytes to ingest and kill bacteria and may account for this and certain of the other variables observed. That such cytophilic antibody may play an important role is suggested by the results of LoBuglio, Cotran, and Jandl (32), who found that IgG that binds to monocytes is critical for phagocytosis of red blood cells. It is possible that we did not see any influence of pooled serum because the specific cytophilic antibody that may have been available in the serum did not bind rapidly enough with the monocytes or was not present in sufficient amounts to influence monocyte killing in our assay system. Since cytophilic antibody significantly influences the phagocytic potential of monocytes, the findings by Schmidt and Douglas that human monocytes lose their receptor sites for IgG after phagocytosis of latex or sheep red blood cells and recover $78 \%-84 \%$ of the sites by $6 \mathrm{~h}$ after phagocytosis (33) provides another possible explana- 
tion for the variation of monocyte function (if there is a variation in recovery time of receptor sites).

As the lymphocyte-monocyte ratio in our preparations was approximately $2-4: 1$, lymphocyte-monocyte interactions could have influenced the ability of monocytes to ingest and destroy the bacteria. A number of workers have demonstrated that lymphocyte factors may activate monocyte-derived macrophages to kill bacteria more effectively $(34,35)$. It is possible, therefore, that lymphocytes present in the monocyte suspensions may have had some effect on monocyte function.

These studies provide information about the phagocytic and bactericidal properties of human monocytes and compare these functions to those of neutrophils. Such information provides a baseline for the further study of factors that influence normal monocyte phagocytic and bactericidal capacity, and facilitates the study of the function of this cell in patients who exhibit impaired host resistance or in whom there is a suspicion of defective cellular immunity.

\section{ACKNOWLEDGMENTS}

We are grateful to Dr. Byron Brown of the Division of Biostatistics, Stanford University Medical Center, for his assistance with the statistical analyses.

These studies were supported by a grant from The John A. Hartford Foundation, Inc.

\section{REFERENCES}

1. Maldonado, J. E., and D. G. Hanlon. 1965. Monocytosis: a current appraisal. Mayo Clin. Proc. 40: 248.

2. Cline, M. J., and R. I. Lehrer. 1968. Phagocytosis by human monocytes. Blood J. Hematol. 32: 423.

3. Root, R. K., A. S. Rosenthal, and D. J. Balestra. 1972. Abnormal bactericidal, metabolic and lysosomal functions of Chediak-Higashi syndrome leukocytes. J. Clin. Invest. 51 : 649.

4. Baehner, R. L., and R. B. Johnston, Jr. 1972. Monocyte function in children with neutropenia and chronic infections. Blood J. Hematol. 40: 31.

5. Diamond, R. D., R. K. Root, and J. E. Bennett. 1972. Factors influencing killing of Cryptococcus neoformans by human leukocytes in vitro. J. Infect. Dis. 125: 367.

6. Øistov, J., K. A. Jensen, and K. Kobayshi. 1928. Studien über Breslauinfektion der Mäuse speziel mit Rücksicht auf die Bedeutung des retikuloendothelial Gewebes. Z. Immunitätsforsch. $55: 34$.

7. Blanden, R. V., G. B. Mackaness, and F. M. Collins. 1966. Mechanisms of acquired resistance in mouse typhoid. J. Exp. Med. 124 : 585.

8. Mackaness, G. B. 1962. Cellular resistance to infection. J. Exp. Med. $116: 381$.

9. Remington, J. S. 1972. The compromised host. Hosp. Pract. $7: 59$.

10. Evans, R., and P. Alexander. 1972. Mechanism of immunologically specific killing of tumour cells hy macrophages. Naturc (I.ond.). 236: 168.
11. Hibbs, J. B., Jr., L. H. Lambert, Jr., and J. S. Remington. 1972. Possible role of macrophage-mediated nonspecific cytotoxicity in tumour resistance. Nat. New Biol. 235 : 48.

12. Böyum, A. 1968. Isolation of mononuclear cells and granulocytes from human blood. Scand. J. Clin. Lab. Invest. Suppl. 97. 21 : 77.

13. Alexander, J. W., D. B. Windhorst, and R. A. Good. 1968. Improved tests for the evaluation of neutrophil function in human disease. J. Lab. Clin. Med. 72: 136.

14. Braude, A. I., and J. Feltes. 1953. Studies in the destruction of staphylococci by human leukocytes: effect of clumping of intracellular and extracellular bacteria on the results obtained with the agar-plate method. $J$. Lab. Clin. Med. 42: 289.

15. Siegel, S. 1956. Nonparametric statistics. McGraw-Hill Book Company, New York.

16. van Furth, R., and Z. A. Cohn. 1968. The origin and kinetics of mononuclear phagocytes. J. Exp. Med. 128: 415.

17. North, R. J. 1970. The relative importance of blood monocytes and fixed macrophages to the expression of cell-mediated immunity to infection. J. Exp. Med. 132: 521.

18. McGregor, D. D., and F. T. Koster. 1971. The mediator of cellular immunity. Cell. Immunol. 2: 317.

19. North, R. J. 1972. The action of cortisone acetate on cell-mediated immunity to infection. J. Exp. Med. 134: 1485.

20. Cline, M. J. 1970. Bactericidal activity of human macrophages: Analysis of factors influencing the killing of Listeria monocytogenes. Infect. Immun. 2: 156.

21. Cohen, A. B., and M. J. Cline. 1971. The human alveolar macrophage: isolation, cultivation in vitro, and studies of morphologic and functional characteristics. J. Clin. Invcst. 50: 1390.

22. Holmes, B., P. G. Quie, D. B. Windhorst, B. Pollara, and R. A. Good. 1966. Protection of phagocytized bacteria from the killing action of antibiotics. Nature (Lond.). 210: 1131.

23. Tan, J. S., C. Watanakunakorn, and J. P. Phair. 1971. A modified assay of neutrophil function: use of lysostaphin to differentiate defective phagocytosis from impaired intracellular killing. J. Lab. Clin. Med. 78: 316.

24. Gardner, D. E., J. A. Graham, F. J. Miller, J. W. Illing, and D. L. Coffin. 1973. Technique for differentiating particles that are cell-associated or ingested by macrophages. Appl. Microbiol. 25 : 471.

25. Strauss, R. R., B. B. Paul, and A. J. Sbarra. 1968. Effect of phenylbutazone on phagocytosis and intracellular killing by guinea pig polymorphonuclear leukocytes. J. Bacteriol. $96: 1982$.

26. Solberg, C. O. 1972. Enhanced susceptibility to infection. Acta Pathol. Microbiol. Scand. Sect. B; Microbiol. Immunol. 80 : 10.

27. Klebanoff, S. J. 1968. Myeloperixodase-halide-hydrogen peroxide antibacterial system. J. Bacteriol. 95: 2131.

28. Schaffner, W., M. A. Melly, J. H. Hash, and M. G. Koenig. 1967. Lysostaphin: an enzymatic approach to staphylococcal disease. I. In vitro stulies. Yale J. Biol. Med. 39: 215. 
29. Davis, W. C., H. Huber, S. D. Douglas, and H. H. Fudenberg. 1968. A defect in circulating mononuclear phagocytes in chronic granulomatous disease of childhood. J. Immunol. 101 : 1093.

30. Rodney, G. E., B. H. Park, D. B. Windhorst, and R. A. Good. 1969. Defective bactericidal activity of monocytes in fatal granulomatous disease. Blood $J$. Hematol. 33 : 813.

31. Huber, H., M. J. Polley, W. D. Linscott, H. H. Fudenberg, and H. J. Müller-Eberhard. 1968. Human monocytes: distinct receptor sites for the third component of complement and for immunoglobulin G. Science (Wash., D. C.). $162: 1281$.
32. LoBuglio, A. F., R. S. Cotran, and J. H. Jandl. 1967. Red cells coated with immunoglobulin G: binding and sphering by mononuclear cells in man. Science (Wash., D. C.). $158: 1582$.

33. Schmidt, M. E., and S. D. Douglas. 1972. Disappearance and recovery of human monocyte IgG receptor activity after phagocytosis. J. Immunol. 109: 914.

34. Patterson, R. J., and G. P. Youmans. 1970. Demonstration in tissue culture of lymphocyte-mediated immunity to tuberculosis. Infect. Immun. 1: 600 .

35. Krahenbuhl, J. L., and J. S. Remington. 1971. In vitro induction of nonspecific resistance in macrophages by specifically sensitized lymphocytes. Infect. Immun. 4: 337. 